\title{
A população urbana e a difusão das cidades de porte médio no Brasil
}

\author{
Urban population and dissemination of medium size cities in Brazil
}

La population urbaine et la diffuson des villes moyennes au Brésil

\author{
Población urbana y difusión de las ciudades de tamaño medio en Brasil \\ Cristiano Stamm* \\ (stamm_br@yahoo.com.br) \\ Jefferson Andronio Ramundo Staduto* \\ (staduto@unioeste.br) \\ Jandir Ferrera de Lima* \\ (jandir.lima@unioeste.br) \\ Yonissa Marmitt Wadi* \\ (yonissa@unioeste.br)
}

Recebido em 10/02/2011; revisado e aprovado em 17/06/2011; aceito em 15/01/2012 Resumo: O presente artigo mostra a evolução das cidades de porte médio no Brasil entre os períodos de 1970 a 2010.
A desconcentração industrial, a mobilidade da fronteira agrícola e os investimentos em infraestrutura que integraram
o interior do Brasil à dinâmica da economia nacional são apontados como os responsáveis pela dispersão espacial
da população brasileira. As cidades de porte médio têm uma posição estratégica potencial para a continuidade da
desconcentração regional no Brasil. Além disso, elas têm induzido principalmente a difusão de atividades mais
modernas por todo território nacional e, consequentemente, uma maior distribuição da população no sistema
urbano brasileiro. A recente emergência dessas cidades no cenário nacional cria condições de implementar projetos
de planejamento urbanos para que não ocorram ou se minimizem os problemas decorrentes da urbanização, que
na história recente causaram e ainda são problemas de difícil solução nas grandes aglomerações populacionais,
tais como as metrópoles.

Palavras-chave: Cidades de porte médio. Sistema urbano. Brasil.

Abstract: This paper shows the evolution of the medium-sized cities in Brazil from 1970 to 2010. The industrial dispersal, the mobility of the agricultural border, and infrastructure investments that integrated the interior of Brazil to the dynamics of the national economy are responsible for the spatial dispersion of Brazilian population. The medium-sized cities have a potential strategic position for the continuity of the regional dispersal in Brazil. Moreover, they have mainly induced the diffusion of more modern activities for all national territory and, consequently, a greater population distribution in the Brazilian urban system. The recent arrival of these cities in the national scenery, creating conditions to implement planning urban projects, prevent or minimize the problems caused by urbanization that in recent history caused and still are problems of difficult solution in the great population agglomerations such as the metropolises.

Key words: Medium-sized cities. Urban system. Brazil.

Résumé: Cet article montre l'évolution des villes de taille moyenne au Brésil, entre les périodes 1970 à 2010. La décentralisation industrielle, la mobilité de la frontière agricole et les investissements dans les infrastructures qui ont intégré l'intérieur du Brésil à la dynamique de l'économie nationale sont considérés comme les responsables de la dispersion spatiale de la population. Les villes de taille moyenne ont un potentiel stratégique pour la poursuite de la décentralisation régionale au pays et elles sont les responsables par la diffusion des activités modernes dans le territoire national et, par conséquent, de la plus grande répartition de la population dans le système urbaine brésilien. L'émergence récente de ces villes sur la scène nationale a crée les conditions de mise en œuvre des projets de planification urbaine pour résoudre des problèmes des grandes agglomérations.

Mots-clés: Les villes moyennes. Système urbaine. Economie urbaine. Brésil

Resumen: El artículo demuestra que la evolución de las ciudades medias brasileñas, en los períodos de 1970 el 2010, incorporan los efectos de la desconcentración industrial, la movilidad de la frontera agrícola y las inversiones en la infraestructura, que han integrado el interior del Brasil a la dinámica de la economía nacional. Por otra parte, han inducido principalmente la difusión de actividades más modernas para todo el territorio e, por lo tanto, una distribución más grande de la población en el sistema urbano brasileño.

Palabras clave: Las ciudades medianas. Sistema urbano. Brasil.

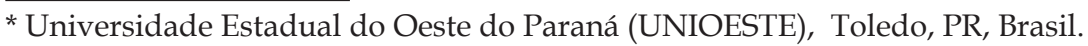




\section{Introdução}

No censo demográfico de 2010, há evidências de que houve um processo de reconcentração da população urbana brasileira nos grandes centros do país, da mesma forma, as evidências apontam para um aumento e dispersão das cidades de porte médio no território brasileiro. Por isso as cidades de porte médio adotam uma posição estratégica potencial para a continuidade da desconcentração regional no Brasil. Essa análise fornecerá elementos para a compreensão da dinâmica da dispersão da população urbana brasileira, bem como para a importância das cidades brasileiras de porte médio neste processo de planejamento regional e urbano. Optou-se pela classificação de cidades de porte médio utilizadas nos trabalhos de Santos (1994), Braga (2005), Maricato (2001), Amorim Filho e Serra (2001), Brito, Horta e Amaral (2001), Andrade e Serra (2001a) e Lima (1998). Para esses autores, as cidades brasileiras de porte médio são os municípios cuja população urbana situava-se entre $100 \mathrm{mil}$ a $500 \mathrm{mil} \mathrm{ha-}$ bitantes, presentes nos Censos Demográficos de 1970 e 2010.

Esse artigo analisa a evolução das cidades brasileiras de porte médio no período de 1970 a 2010. A escolha desses períodos devese a duas particularidades: a primeira é a insuficiência de centros urbanos intermediários com dinamismo demográfico e econômico na década de 1970; e a segunda, que no ano 2010 foi lançado o último Censo Demográfico do Instituto Brasileiro de Geografia e Estatística (IBGE), principal fonte de dados dessa análise. Essa temática avança sobre um possível "novo papel" reservado às cidades brasileiras de porte médio na atual ordem econômica nacional/mundial.

De acordo com Pereira (2005), um dos critérios mais utilizados na definição de cidades de porte médio tem sido a dimensão demográfica. Ainda de acordo com a autora, quando se debate sobre cidades de porte médio, trata-se mais de uma noção do que de um conceito. Vale ressaltar que o enfoque é dado às cidades de porte médio ao invés das cidades pequenas, por ser necessário o amparo de uma inevitável escala mínima urbana, mesmo sabendo que uma cidade média esteja fortemente associada a sua funcionalidade em seu entorno. Segundo Amorim Filho e Serra (2001), as cidades de porte médio em relação aos centros urbanos de menor porte apresentam condições e vantagens locacionais para sediar vários setores de atividade contribuindo para a tendência de interiorização.

Além dessa parte introdutória, este artigo possui mais quatro seções: Na segunda parte, são feitos alguns apontamentos sobre hierarquia das cidades, procurando evidenciar os atributos. Na terceira, é analisada a evolução das cidades de porte médio no Brasil, mostrando seu surgimento e sua importância dentro da esfera econômica nacional. A dispersão das cidades de porte médio pelo território nacional contempla a quarta parte do trabalho, em que são confeccionados algumas tabelas e mapas e suas respectivas análises. As considerações finais sumariam este artigo.

\section{Redes urbanas e hierarquia das cidades: elementos teóricos}

A cidade é um importante local de vitalidade econômica, cultural e social, além de ser o centro das decisões políticas. Ela é um fenômeno de aglomerados industriais, comerciais, financeiros, religiosos e de lazer da população, que procuram satisfazer seu bem-estar social, a que Castells (1983) denominou de aglomerados funcionais, ou seja, esses aglomerados têm suas funções. Por isso as cidades, dentro de determinadas áreas podem ser classificadas hierarquicamente, normalmente, de acordo com suas funções econômicas. As faixas hierárquicas geralmente são expressas por uma divisão de classes de tamanhos de população. O tamanho populacional das cidades pode indicar suas funções necessárias mínimas para satisfazer as necessidades dessa população.

As cidades de menor porte são tidas apenas como um centro mediador do comércio local com as regiões. As cidades de médio porte, além das funções das cidades de menor porte, apresentam um maior peso econômico e assumem a função de suprir as demandas dos produtos que não são produzidos nos centros de menor porte. As cidades de grande porte (ou metropolitanas) se distinguem pelo maior volume populacional, por serem polarizadoras de centros menores, e caracterizam-se 
por apresentar uma mancha de ocupação derivada de conurbação (CHRISTALLER, 1966; GEDDES, 1994; IPEA et al., 1999).

Apesar das diferenças de tamanhos, as cidades relacionam-se entre si, assumindo diferentes tipos de relações no espaço, formando as redes de cidades. Para Ferrera de Lima (2004), a organização dessas redes serve para otimizar as economias de proximidades, ou seja, os meios de transporte, a distribuição da população e a oferta de bens de serviços. Essas redes refletem a organização e segmentação do espaço. Essas redes reorganizam o espaço, criam novas aglomerações, novos centros, novas áreas de mercado baseadas sobre uma nova conjuntura econômica e potencial da produção. Em certos casos, conforme Lacour e Gaschet (2002), esses novos centros potenciais provêm da integração periférica com um polo, estimulada pelo melhoramento das redes de transporte e comunicações, diminuindo as distâncias.

O papel do polo e da periferia na organização da rede urbana não é atual. Os estudos clássicos de Friedman (1972) apontavam a hierarquia funcional das cidades, como segue: a) cidade primaz (primate city), que exerce funções de alta complexidade, com especialização em serviços de saúde e educação, equipamentos de precisão, financeiros, comunicações, governamentais e, também, como áreas que tenham maiores mercados potenciais; b) cidades regionais (regional city), polarizadas por centros de reconhecida importância na rede urbana regional (têm influências das cidades primazes) e apresentam uma abrangência de polarização mais restrita; c) cidades sub-regionais (provincial city), que são os centros comerciais inferiores, esporadicamente com alguns centros industriais; e, d) cidades locais (local service city), exclusivamente agrícolas, com menor volume populacional e densidade, mas integradas por uma dinâmica socioeconômica comum. Podem surgir nesse mesmo contexto hierárquico, cidades satélites direcionadas para economias mais simples ou atividades como manufatura, educação, entretenimento, administração entre outras.

Apesar da classificação de Friedman (1972), os avanços mais recentes nos mecanismos da polarização foram dados por Krugman (1991), com seus estudos da nova economia geográfica. Segundo Krugman (1991) e Krugman, Venables e Fujita (2004), a polarização é o resultado da interação entre baixos custos de transporte e de relações interindustriais de cooperação e concorrência entre cidades específicas. Por isso as cidades periféricas aliam custos expressivos de transporte com uma relação de dependência nas atividades de transformação e serviços. Isso faz com que as cidades periféricas tenham um custo maior de produção e distribuição aliada a problemas com retorno de escala. Com isso, custos moderados de produção associados aos retornos de escala e custos de serviços pouco significativos geram tendências à concentração geográfica dos agentes econômicos, consequentemente, no padrão de localização das atividades produtivas e na organização espacial da economia.

Essa discussão em torno da polarização nos remete a uma constatação: a cidade é um sistema que integra um outro sistema, mas, devido às suas diferenças, passam a coexistir lugares centrais de graus diferentes, cujo papel é estruturar e organizar do espaço geográfico de uma região. Por isso, no caso dessa análise, as cidades serão classificadas como: a cidade primaz, como um lugar central de ordem superior; as cidades locais, como lugares centrais de ordem inferior; e o restante das cidades (as cidades regionais e sub-regionais), como centros urbanos intermediários. Dessa forma, os centros urbanos tidos como intermediários serão, para efeito de análise, as cidades de porte médio, objeto deste artigo.

\section{A evolução da urbanização no Brasil}

No Brasil, na década de 1970, os primeiros estudos sobre as cidades de porte médio definiam esses centros urbanos como aqueles que possuíam alguns atributos sistematizados por Amorim Filho (1984), tais como:

- Interações constantes e duradouras tanto com seu espaço regional subordinado, quanto com aglomerações urbanas de hierarquia superior;

- Tamanho demográfico e funcional suficiente para oferecer um leque bastante largo de bens e serviços ao espaço microrregional e desenvolverem economias urbanas necessárias ao desempenho eficiente de atividades produtivas; 
- Capacidade de receber e fixar os migrantes de cidades menores ou da zona rural, por meio do oferecimento de oportunidade de trabalho, interrompendo o movimento migratório na direção das grandes cidades, já saturadas;

- Condições necessárias ao estabelecimento de relações de dinamização com o espaço rural microrregional que envolve; e

- Diferenciação do espaço intraurbano, com um centro funcional já bem individualizado e uma periferia dinâmica, como as grandes cidades, isto é, por intermédio da multiplicação de novos núcleos habitacionais periféricos.

As cidades de população entre $50 \mathrm{mil}$ e 250 mil habitantes englobariam todos os atributos requeridos acima. Porém, apesar dos elementos sistematizados por Amorim Filho (1984), ocorreram modificações nas funções típicas das cidades de porte médio, principalmente, devido às transformações e evoluções do sistema urbano vigente. Além disso, os limites demográficos na maioria dos estudos foram ampliados, e o que definia cidades de porte médio não satisfaz mais a atual configuração socioeconômica. Assim, pode-se inferir que uma cidade de porte médio deve dar suporte a uma quantidade importante de atividades e serviços que exigem para existir uma população não inferior a 100 mil habitantes.

É importante mencionar o que antecede às cidades de porte médio no Brasil, ou seja, o processo da intensificação e formação das metrópoles nacionais. Esse processo causou uma intensa urbanização, baseado na concentração demográfica e econômica, principalmente entre o eixo Rio de Janeiro-São Paulo.

Após a década de 1950, ampliou-se o número de cidades brasileiras de porte médio, num contexto de redefinição do porte dos núcleos urbanos nacionais, devido principalmente pelo processo de industrialização da economia brasileira via substituição de importações, motivo o qual levou a um intenso fluxo migratório ou também o chamado "êxodo rural", para os grandes centros, moldando, desde então, a rede urbana nacional.

Na década de 1960, o avanço da urbanização contribuiu para a criação das metrópoles nacionais, estas, institucionalizadas a partir da década de 1970. Esse fenômeno pode ser explicado, basicamente, através do aumento do setor de serviços. Segundo Andrade e Serra (2001b), a diminuição da População Economicamente Ativa (PEA) e as mudanças nos padrões tecnológicos associaram a industrialização com a urbanização. Com isso, os serviços que dão suporte à estrutura industrial tornam-se uma característica da dispersão dos centros urbanos. Assim, conforme relata Kon (1999), os economistas reconhecem que o setor de serviços é um fenômeno urbano e que, em alguns estudos, se referem a um forte relacionamento entre a proliferação dos serviços e ao amplo processo de urbanização. A evolução desse processo de urbanização pode ser visualizada na Tabela 1, que mostra também a população total e a divisão da população urbana e rural do país.

Tabela 1 - Evolução da população e do índice de urbanização no Brasil (1940-2010)

\begin{tabular}{c|ccccc}
\hline Ano & População Total & População Urbana & População Rural & Urbanização (\%) \\
\hline 1940 & 41.236 .315 & 12.880 .182 & 28.356 .133 & 31,24 \\
1950 & 51.944 .397 & 18.782 .891 & 33.161 .506 & 36,16 \\
1960 & 70.070 .457 & 31.303 .034 & 38.767 .423 & 44,67 \\
1970 & 93.139 .037 & 52.084 .984 & 41.054 .053 & 55,92 \\
1980 & 119.002 .706 & 80.436 .409 & 38.566 .297 & 67,59 \\
1991 & 146.825 .475 & 110.990 .990 & 35.834 .485 & 75,59 \\
2000 & 169.799 .170 & 137.953 .959 & 31.845 .211 & 81,25 \\
2010 & 190.755 .799 & 160.925 .792 & 29.830 .007 & 84,36 \\
\hline
\end{tabular}

Fonte: Elaborado por Stamm (2013) a partir do IBGE (2003 e 2010).

Apesar do aumento considerável da população total (362\%) entre 1940-2010, é interessante observar que o aumento da popu- lação urbana foi de $1.049 \%$. A população rural cresceu apenas $5,20 \%$, refletindo na conhecida evolução da urbanização brasileira, que pas- 
sou de $31,24 \%$, em 1940, para 84,36\% em 2010. Embora a população rural tenha perdido, através do êxodo rural, cerca de 11,2 milhões de pessoas entre 1970 e 2010, a alta taxa de natalidade também é um fator que contribuiu para o crescimento da população urbana.
A Tabela 2 mostra a evolução das metrópoles nacionais em termos de população no total nacional, em que se observa uma diminuição do ritmo de crescimento das Regiões Metropolitanas (RMs) no Brasil.

Tabela 2 - População residente nas Regiões Metropolitanas no Brasil - 1970 a 2010*

\begin{tabular}{c|c|c|c|c|c}
\hline Regiões & \multicolumn{5}{c}{ População Residente } \\
\cline { 2 - 6 } Metropolitanas & $\mathbf{1 9 7 0}$ & $\mathbf{1 9 8 0}$ & $\mathbf{1 9 9 1}$ & $\mathbf{2 0 0 0}$ & $\mathbf{2 0 1 0}$ \\
\hline Belém & 656.351 & 1.000 .349 & 1.401 .305 & 1.794 .981 & 2.101 .883 \\
Fortaleza & 1.038 .041 & 1.581 .588 & 2.401 .878 & 2.975 .703 & 3.615 .767 \\
Recife & 1.792 .688 & 2.348 .362 & 2.919 .979 & 3.335 .704 & 3.690 .547 \\
Salvador & 1.148 .828 & 1.772 .018 & 2.496 .521 & 3.018 .285 & 3.573 .973 \\
Belo Horizonte & 1.605 .663 & 2.541 .788 & 3.515 .542 & 4.342 .367 & 5.414 .701 \\
Rio de Janeiro & 7.082 .404 & 9.018 .637 & 9.814 .574 & 10.872 .768 & 11.835 .708 \\
São Paulo & 8.137 .401 & 12.588 .439 & 15.444 .941 & 17.834 .664 & 19.683 .975 \\
Curitiba & 820.766 & 1.441 .743 & 2.063 .654 & 2.725 .629 & 3.174 .201 \\
Porto Alegre & 1.531 .168 & 2.232 .370 & 3.147 .010 & 3.655 .834 & 3.958 .985 \\
\hline Total RMs & 23.813 .310 & 34.525 .294 & 43.205 .404 & 50.555 .935 & 57.049 .740 \\
Total Brasil & 93.139 .037 & 119.002 .706 & 146.825 .475 & 169.799 .170 & 190.755 .799 \\
\hline \% RMs/Brasil & 25,57 & 29,01 & 29,43 & 29,77 & 29,91 \\
\hline
\end{tabular}

Fonte: Elaborado por Stamm (2013) a partir do IBGE (2003 e 2010).

* Nessa tabela são apresentadas apenas as primeiras metrópoles institucionalizadas na década de 1970.

Nessa tabela, fica evidenciada a estagnação relativa da participação da população das RMs no total nacional em torno de $29 \%$. Com isso, a principal tendência do processo de urbanização no Brasil é uma menor participação das regiões metropolitanas na população do país. Por isso ocorre o fenômeno de "desmetropolização", indutor da difusão de atividades mais modernas por todo território nacional e, consequentemente, uma maior distribuição da população no sistema urbano brasileiro - elementos esses que nos fazem compreender a tendência da "desmetropolização". Santos (1994) afirmou que esse processo de transformação do espaço, pelo qual o Brasil passou na década de 1980 e início de 1990, foi um fenômeno paralelo de metropolização e desmetropolização.

No caso dos dois centros principais - São Paulo e Rio de Janeiro - vale ressaltar que a infraestrutura básica existente nessas cidades, as quais estavam ligadas ao comércio internacional, permitiu a localização das indústrias nesses dois principais polos brasileiros e em suas áreas mais próximas, explicando a concentração das atividades econômicas nesses dois centros primazes. Porém, a partir da década de 1970, houve um processo de desconcentração econômica e industrial, fato que ocorreu principalmente na Região Metropolitana de São Paulo (RMSP). Segundo Diniz (1993) e Andrade e Serra (2001a), esse processo foi composto de duas fases: na primeira, ocorreu uma relativa dispersão da produção industrial no País como um todo; e na segunda fase, ocorreu uma relativa reconcentração da atividade industrial dentro de um polígono (chamado de polígono industrial brasileiro), delimitado pelos seus vértices, as regiões de: Belo Horizonte (MG); Uberlândia (MG); Maringá (PR); Porto Alegre (RS); Florianópolis (SC) e São José dos Campos (SP) (Mapa 1). 


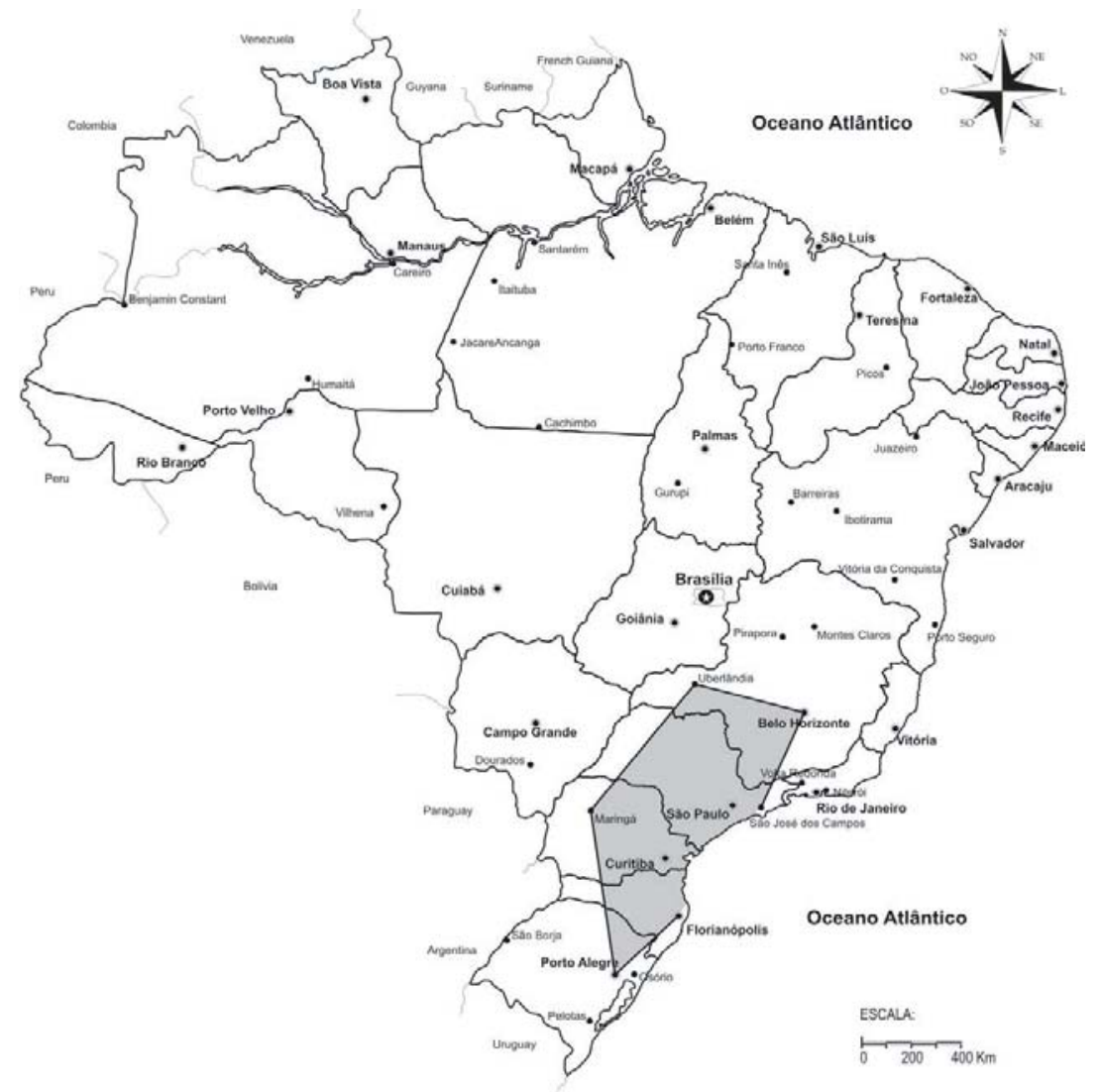

Mapa 1 - Polígono industrial brasileiro - 1991

Fonte: Elaborado por Stamm (2005) a partir de Andrade e Serra (2001a, p. 346) - Malha regional digital do Brasil - IBGE (1997).

Bernardes (2003) acrescentou múltiplos elementos que podem levar ao processo de desconcentração e, consequentemente, ao crescimento da urbanização nacional. Entre eles, enfatizam-se as dispersões da indústria e a modernização do campo, a proximidade das indústrias agrícolas e as novas formas de consumo material e de consumo imaterial que, mesmo sendo um fenômeno geral, teve particular expressão em áreas mais desenvolvidas do país. A partir do exposto e de acordo com Andrade e Serra (2001b), é neste momento do desenvolvimento brasileiro (década de 1970) que as cidades de porte médio surgem como alternativa de difusão do desenvolvimento econômico no país.

Alguns dados, conforme Gráfico 1, confirmam a tendência do "surgimento" e respectivo aumento das cidades de porte médio no Brasil.

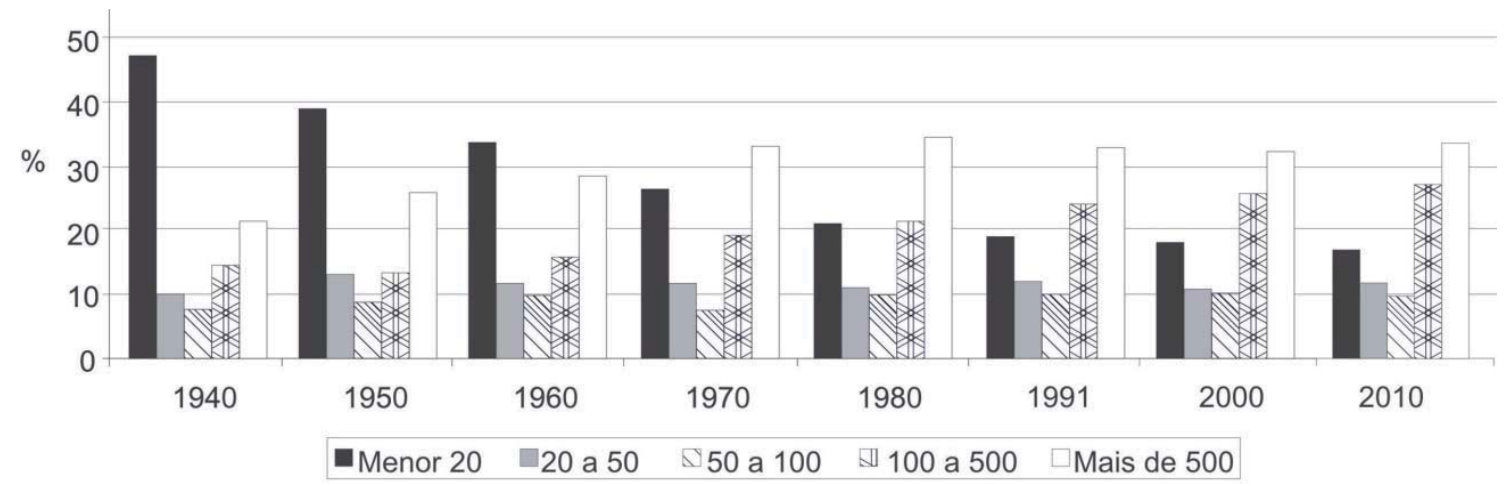

Gráfico 1 - Distribuição da população urbana segundo sua classe de tamanho - 1940 a 2010 Fonte: Adaptado por Stamm (2005 e 2013) a partir de Brito, Horta e Amaral (2001) e IBGE (2011a). 
No contexto geral, entre 1940 a 2010, o número total de municípios no país aumentou consideravelmente, passando de 1.574 para 5.565, um incremento de 3.991 municípios. Os municípios com população urbana inferior a 20 mil habitantes passaram de 857 para 4.471. Apesar desse aumento (421,7\%), pode-se observar no Gráfico 1 que os municípios com menos de 20 mil habitantes em 1940 abrigavam quase $50 \%$ da população urbana no país, e, em 2010, o total da população urbana nessas cidades era um pouco maior do que $17 \%$.

As pequenas oscilações dos municípios com 20 mil a 50 mil habitantes urbanos (597 municípios em 1940, e 618 municípios em 2010, respectivamente), também se refletiram num crescimento percentual muito pequeno, passando de $10 \%$ do total de habitantes urbanos residentes nesses municípios para cerca de $12 \%$, apresentando, ao longo do período, participações relativamente constantes. Pode-se dizer, portanto, que os municípios nessa faixa mantiveram sua posição ao longo do tempo.

O número de municípios representado pelo extrato populacional entre 50 mil e 100 mil habitantes urbanos mais que dobrou no período, passando de 97, em 1940, para 226, em 2010. Entretanto o percentual de participação desses municípios no total da população urbana do país pouco cresceu, passando de cerca de $8 \%$ para quase $10 \%$ no período.

Os municípios enquadrados como cidades de porte médio aumentaram considera- velmente sua participação na população total do país; ou seja, o que era representado, em 1940, por cerca de $15 \%$ da população urbana do país, em 2010 chegou a abrigar pouco mais de $27 \%$ dessa população. Todavia, através do crescimento acelerado das cidades de porte médio, nota-se que há continuidade da metropolização no Brasil.

Já os municípios com mais de $500 \mathrm{mil}$ habitantes urbanos também cresceram, principalmente entre as décadas de 1940 e 1980, passando nesse período de $21 \%$ para cerca de $35 \%$ da população do país. Entre as décadas seguintes, esse percentual praticamente se manteve estável na casa dos 33\% a 34\%.

\section{A difusão das cidades de porte médio no território brasileiro}

Com a análise dos dados exposta no item anterior, e aprofundando o relato histórico do processo de urbanização no Brasil, ficam evidentes duas situações no país: a) a evolução das cidades de porte médio no entorno ou com influência das metrópoles e capitais estaduais; e b) o crescimento e desenvolvimento de cidades interioranas de porte médio em áreas não metropolitanas (conforme a Tabela 3). Essas situações trazem três explicações plausíveis: o papel indutor da desconcentração industrial iniciada na década de 1970, a expansão da fronteira agrícola e as deseconomias de aglomeração dos grandes centros urbanos.

Tabela 3 - Distribuição da população urbana segundo sua classe de tamanho - 1970 a 2010

\begin{tabular}{l|c|c|c|c|c}
\hline \multirow{2}{*}{ Cidades } & \multicolumn{5}{c}{ População urbana total (\%) } \\
\cline { 2 - 6 } & $\mathbf{1 9 7 0}$ & $\mathbf{1 9 8 0}$ & $\mathbf{1 9 9 1}$ & $\mathbf{2 0 0 0}$ & $\mathbf{2 0 1 0}$ \\
\hline Cidades não metropolitanas & \multicolumn{5}{c}{$\mathbf{c}$} \\
\hline$<20.000$ & 25,82 & 20,92 & 19,07 & 18,57 & 16,57 \\
\hline 20.000 a $<50.000$ & 9,48 & 9,91 & 11,29 & 10,60 & 10,62 \\
\hline 50.000 a $<100.000$ & 5,77 & 7,40 & 8,07 & 8,28 & 8,02 \\
\hline $\mathbf{1 0 0 . 0 0 0}$ a $<500.000$ & $\mathbf{1 0 , 2 9}$ & $\mathbf{1 4 , 8 4}$ & $\mathbf{1 6 , 4 1}$ & $\mathbf{1 7 , 3 1}$ & $\mathbf{1 6 , 6 2}$ \\
\hline Mais de 500.000 & 0,00 & 0,00 & 2,23 & 4,25 & 6,87 \\
\hline Total não metropolitanas & 51,36 & 53,07 & 57,07 & 59,02 & 58,70 \\
\hline Cidades metropolitanas & 1,09 & 0,43 & 0,27 & 0,28 & 0,55 \\
\hline$<20.000$ & 2,56 & 1,49 & 1,15 & 0,87 & 1,22 \\
\hline 20.000 a < 50.000 & 2,03 & 3,10 & 2,16 & 2,30 & 1,91 \\
\hline 50.000 a < 100.000 & $\mathbf{7 , 4 7}$ & $\mathbf{6 , 6 2}$ & $\mathbf{8 , 0 2}$ & $\mathbf{8 , 7 8}$ & $\mathbf{1 0 , 7 1}$ \\
\hline $\mathbf{1 0 0 . 0 0 0}$ a < 500.000 & 1,40 & 4,19 & 4,76 & 4,91 & 4,47 \\
\hline Mais de 500.000 & 14,55 & 15,83 & 16,36 & 17,15 & 18,35 \\
\hline Total metrop. s/núcleos & 34,09 & 31,11 & 26,56 & 23,83 & 22,95 \\
\hline Núcleos metropolitanos & 48,64 & 46,93 & 42,93 & 40,98 & 41,30 \\
\hline Total metropolitanas & 52.084 .984 & 80.436 .409 & 110.990 .990 & 137.697 .439 & 160.925 .792 \\
\hline Total abs. da pop. urbana
\end{tabular}

Fonte: Adaptada por Stamm (2005 e 2013) a partir de Brito, Horta e Amaral (2001) e IBGE (2011a). 
Os resultados de ambas as situações demonstram que, até o início da década de 1980, com a "explosão" da população urbana, caminhou-se na direção de uma concentração nas grandes cidades, com destaque para cidades metropolitanas com mais de 500 mil habitantes, passando de 1,4\% em 1970 para $4,19 \%$ em 1980, apresentando uma relativa estabilização nos décadas posteriores $(4,76 \%$, $4,91 \%$ e $4,47 \%$, respectivamente). No decênio de 1980, as cidades de porte médio não metropolitanas começavam um ciclo de expansão acompanhadas, no decênio de 1991, das cidades com mais de 500 mil habitantes não metropolitanas. Essas cidades iniciavam uma nova dinâmica em relação às cidades metropo- litanas acima de 100 mil habitantes, revertendo o processo de crescimento. As cidades acima de 100 mil habitantes não metropolitanas cresceram proporcionalmente mais do que as cidades metropolitanas desse porte, em todo o período; ou seja, as primeiras passaram de 10,29\% em 1970 para 23,49\% em 2010, enquanto as segundas representavam $8,47 \%$ em 1970 e atingiram um percentual de 15,18\% em 2010.

No Gráfico 2, é exposto o crescimento da população urbana residente nas cidades de porte médio não metropolitanas quando comparadas com as cidades de porte médio metropolitanas, fato que evidencia a dispersão da população urbana e o crescimento do número de cidades de porte médio no país.

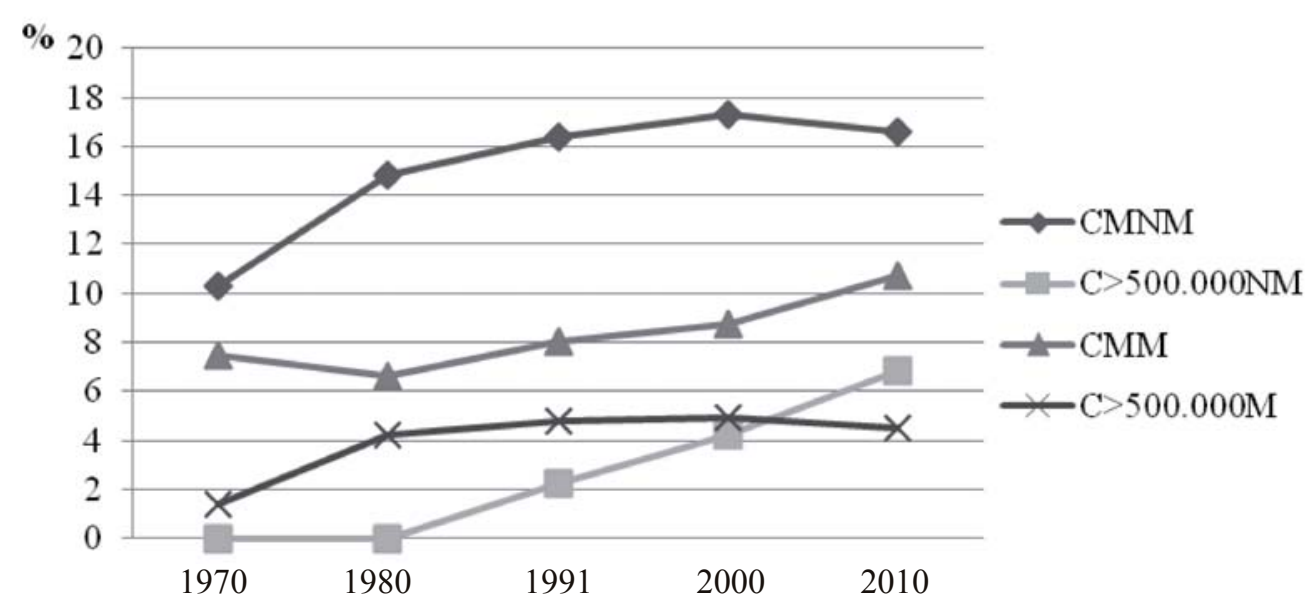

Gráfico 2 - Evolução da população urbana nas cidades de porte médio metropolitanas e não metropolitanas - 1970 a 2010

Fonte: Elaborado por Stamm (2005 e 2013) a partir dos dados da Tabela 3.

Notas: CMNM - Cidades de porte médio não metropolitanas

C>500NM - Cidades com mais de 500 mil habitantes não metropolitanas

CMM - Cidades de porte médio metropolitanas sem os núcleos

C>500M - Cidades metropolitanas com mais de 500 mil habitantes sem os núcleos.

As atuais cidades de porte médio não metropolitanas exerceram grande atração de fluxos migratórios, e algumas delas atingiram e/ou irão atingir um estágio submetropolitano, cuja dimensão varia segundo as dinâmicas de cada região brasileira. Nessa perspectiva de crescimento, as cidades de porte médio não só cumpriram o papel de contenção dos fluxos migratórios, que se dirigiam para os grandes centros em períodos anteriores, mas também representam a dispersão da população nacional, a qual está relacionada à desconcentração industrial e à mobilidade da fronteira agrícola.

A Tabela 4 apresenta dados referentes ao número absoluto de municípios por classe de tamanho e a percentagem de sua respectiva população total. 
Tabela 4 - Quantidade de municípios brasileiros e sua participação percentual na população total de acordo com sua classe de tamanho (1970-2010)

\begin{tabular}{|c|c|c|c|c|c|c|c|c|c|c|}
\hline \multirow{2}{*}{$\begin{array}{c}\text { Classe de } \\
\text { tamanho dos } \\
\text { municípios (mil } \\
\text { habitantes) }\end{array}$} & \multicolumn{2}{|c|}{1970} & \multicolumn{2}{|c|}{1980} & \multicolumn{2}{|c|}{1991} & \multicolumn{2}{|c|}{2000} & \multicolumn{2}{|c|}{2010} \\
\hline & mun. & $\%$ & mun. & $\%$ & mun. & $\%$ & mun. & $\%$ & mun. & $\%$ \\
\hline$<20$ & 2.875 & 28,1 & 2.758 & 21,3 & 3.095 & 19,6 & 4.022 & 19,8 & 3914 & 17,1 \\
\hline Entre $>20$ e $<50$ & 828 & 26,4 & 859 & 22,1 & 930 & 19,2 & 958 & 16,9 & 1043 & 16,4 \\
\hline Entre $>50$ e $<100$ & 158 & 11,0 & 236 & 13,1 & 281 & 13,1 & 303 & 12,4 & 325 & 11,7 \\
\hline $\begin{array}{l}\text { Entre }>100 \text { e } \\
<500\end{array}$ & 80 & 15,5 & 120 & 19,1 & 160 & 21,7 & 193 & 23,3 & 245 & 25,5 \\
\hline $\begin{array}{l}\text { Mais de }>500 \text { mil } \\
\text { Total Brasil }\end{array}$ & $\begin{array}{c}11 \\
3.952\end{array}$ & $\begin{array}{l}19,0 \\
100\end{array}$ & $\begin{array}{c}18 \\
3.991\end{array}$ & $\begin{array}{l}24,4 \\
100\end{array}$ & $\begin{array}{c}25 \\
4.491\end{array}$ & $\begin{array}{l}26,5 \\
100\end{array}$ & $\begin{array}{c}31 \\
5.507\end{array}$ & $\begin{array}{l}27,6 \\
100\end{array}$ & $\begin{array}{c}38 \\
5565\end{array}$ & $\begin{array}{l}29,3 \\
100\end{array}$ \\
\hline
\end{tabular}

Fonte: Elaborada por Stamm (2013) a partir de IBGE/Censo Demográfico de 1970, 1980, 1991, 2000 e 2010.

Nota: Mun. - Número absoluto de municípios

\% - \% na população total.

Apesar da emancipação de 1.613 municípios entre 1970 e 2010 (que correspondeu a um aumento de $40,8 \%$ no total de municípios no país), observa-se um incremento de $36,14 \%$ no total de municípios de pequeno porte, de até 20 mil habitantes, mesmo com uma diminuição na participação da população no total desses municípios de $28,1 \%$ em 1970, para $17,1 \%$ em 2010. Para os municípios da segunda faixa, houve um aumento de 215 municípios no período, mas a participação da população total, assim como o anterior, diminuiu cerca de $10 \%$ (de $26,4 \%$ para $16,4 \%$ ).

Cabe destacar o aumento dos municípios com população acima de 100 mil habitantes que, em 1970, representavam 2,3\% do total de municípios no Brasil, com cerca de 34,5\% da população nacional e que, em 2010, já eram $5,09 \%$ do total de municípios brasileiros, o que representava $54,7 \%$ da população total.

Os Mapas 2 e 3 expressam a dispersão das cidades de porte médio no Brasil para os períodos de 1970 e 2010 respectivamente.

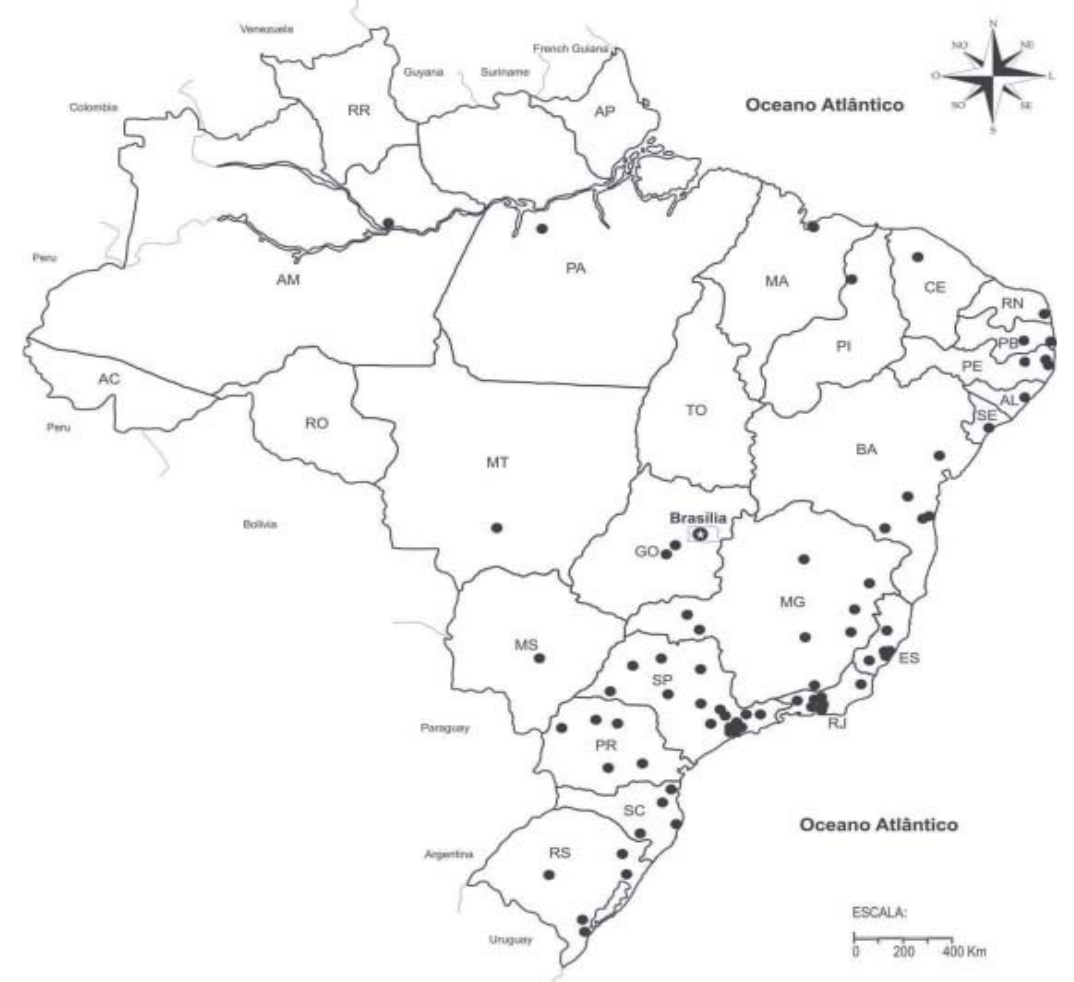

Mapa 2 - Dispersão das cidades de porte médio no Brasil - 1970 Fonte: Elaborado por Stamm (2005) a partir dos dados do IBGE, Censo Demográfico (1970) - Malha municipal digital do Brasil de 1997. 
Esses mapas apresentam apenas as cidades de porte médio no período, aquelas cidades cuja população urbana apresentava-se entre 100 mil e 500 mil habitantes. Observa-se que algumas cidades do Mapa 2, de 1970, não aparecem no Mapa 3, de 2010. Isso se deve, basicamente, a três fatores: a) algumas cidades apresentaram um forte poder de atração populacional, fazendo com que ultrapassassem o limite superior de 500 mil habitantes; b) as cidades essencialmente agrícolas, e que na década de 1970 ocupavam muita mão de obra, perderam população devido ao êxodo rural, ficando, assim, abaixo dos 100 mil habitantes; e c) por existirem cidades de grandes proporções territoriais com vários distritos administrativos que, por sua vez, podem ter sido desmembramentos em outras cidades (emancipação), uma vez que, como já visto na Tabela 4, houve um incremento de 1.613 municípios no Brasil entre o período (19702010).

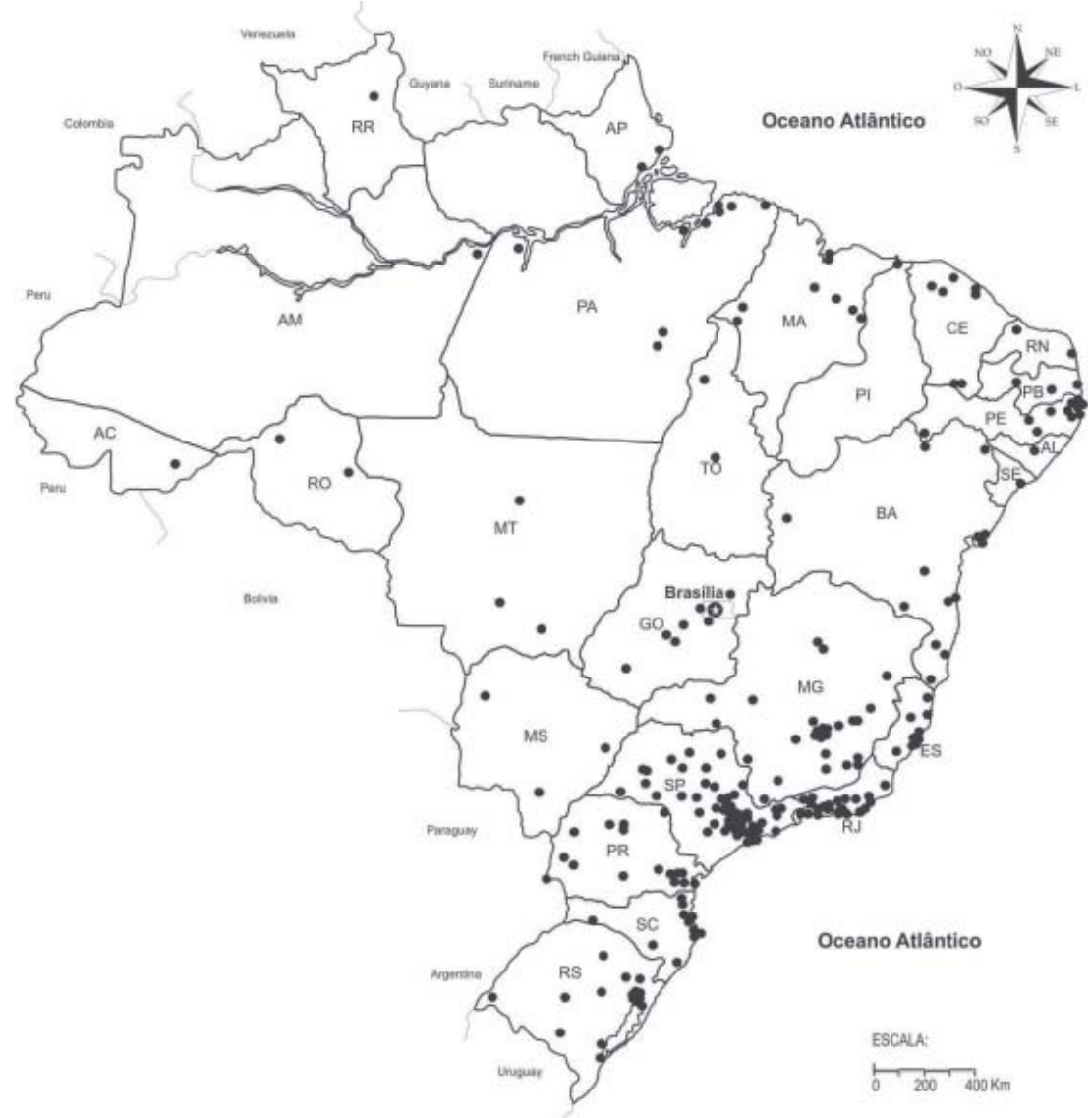

Mapa 3 - Dispersão das cidades de porte médio no Brasil - 2010

Fonte: Elaborado por Stamm (2013) a partir dos dados do IBGE, Censo Demográfico (2011b) Malha municipal digital do Brasil de 1997.

Comparando o Mapa 3 e o Mapa 4, observa-se o perfil da dispersão das cidades de porte médio pelo Brasil. Em 1970 havia um aglomerado de cidades de porte médio basicamente formado pelas regiões Sul e Sudeste. As duas regiões representavam $71,25 \%$ do total das cidades de porte médio do Brasil que, na época, somavam um total de 80 municípios. No ano de 2010, o percentual das regiões Sul e Sudeste diminuiu para $67,76 \%$, um indício da dispersão ou do crescimento da população em outras regiões do Brasil, que atualmente somam um total de 245 municípios.

Pela dispersão espacial das cidades, nota-se que a difusão se dá no sentido leste $\rightarrow$ oeste do país, tornando as cidades de porte médio em plataformas de bens e serviços para as cidades locais e sub-regionais do Centro-Oeste e Norte do Brasil, tanto que a fronteira agrícola se esgota na região 
Sul do Brasil no início dos anos 1980, e entre 1980 e 2010 ela amplia tanto no número de cidades de porte médio (passando de 20 para 44), quanto na participação da população residente (passando de 3.305.869 habitantes em 1980 para 8.634.378 habitantes em 2010). Verifica-se que o movimento expansivo do crescimento da população ao longo do território, depois da ocupação das terras itinerantes, fez com que o processo de crescimento populacional se tornasse intensivo e percolativo ${ }^{1}$, marcando apenas algumas cidades. $\mathrm{O}$ mesmo processo ocorre no Centro-Oeste e no Norte do Brasil. Na comparação do Mapa 2 e do Mapa 3, ainda se mostra que o processo de dispersão da população de forma expansiva continua marcante nas regiões do Cerrado e da Amazônia.

Provavelmente, dentro de mais 20 anos, com a ocupação completa da fronteira agrícola nessas áreas, o processo se reverterá de forma mais intensiva e também percolativa. Essa constatação é confirmada por Santos (1994) e Silveira (2003) ao afirmarem que as cidades de porte médio estão ligadas a formas modernas de produção e consumo estimuladas pela renda da agricultura moderna e um parque industrial associado ao setor primário. Alguns dados atualizados pelo IBGE (2011b) confirmam que os municípios menos populosos tiveram baixas taxas de crescimento no período 2000-2011 (Figura 1).

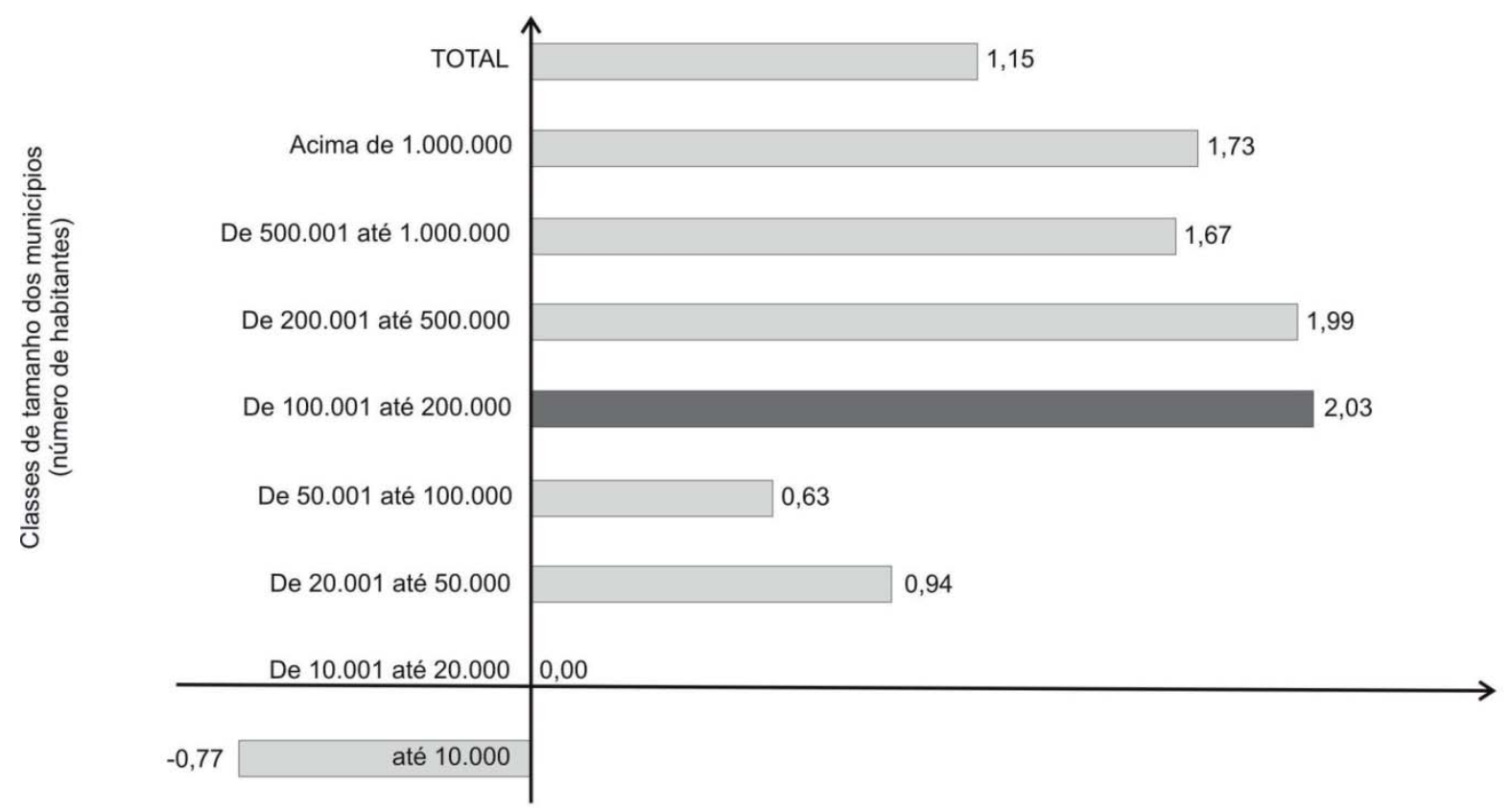

Taxas de Crescimento (\%)

Figura 1 - Taxa geométrica de crescimento anual (\%), segundo as classes de tamanho dos municípios (número de habitantes entre 2000-2011)

Fonte: IBGE (2011b).

Para o IBGE (2011b), as significativas taxas de crescimento dos grandes municípios em volume populacional (acima de 500 mil habitantes) foram influenciadas "pelo componente vegetativo e por um saldo mi-

\footnotetext{
${ }^{1}$ Num processo de difusão espacial percolativa, apesar das forças de propagação atingir todo o território, o processo de desenvolvimento econômico continua desigual (FERRERA DE LIMA, 2004 apud TSCHÁ et al., 2009).
}

gratório que prevalece favorável à imigração, embora possam estar experimentando reduções no transcurso das últimas quatro décadas". Como afirmado por Santos (1994) e Silveira (2003), acima, e confirmado pelo IBGE (2011b) na Figura 1, os municípios de porte médio (aqueles entre 100 e $500 \mathrm{mil}$ habitantes) protagonizaram os crescimentos demográficos mais expressivos nos últimos anos, destacando-se aqueles cujas economias 
estão voltadas ao agronegócio, às atividades petrolíferas e os que demandam mão de obra para a construção civil.

Para melhor ilustrar e examinar essa situação, comparou-se a localização das ci- dades de porte médio (Mapa 4 - A) com a conformação da rede urbana brasileira apresentada por meio dos dados do IPEA et al. (1999) (Mapa 4 - B).
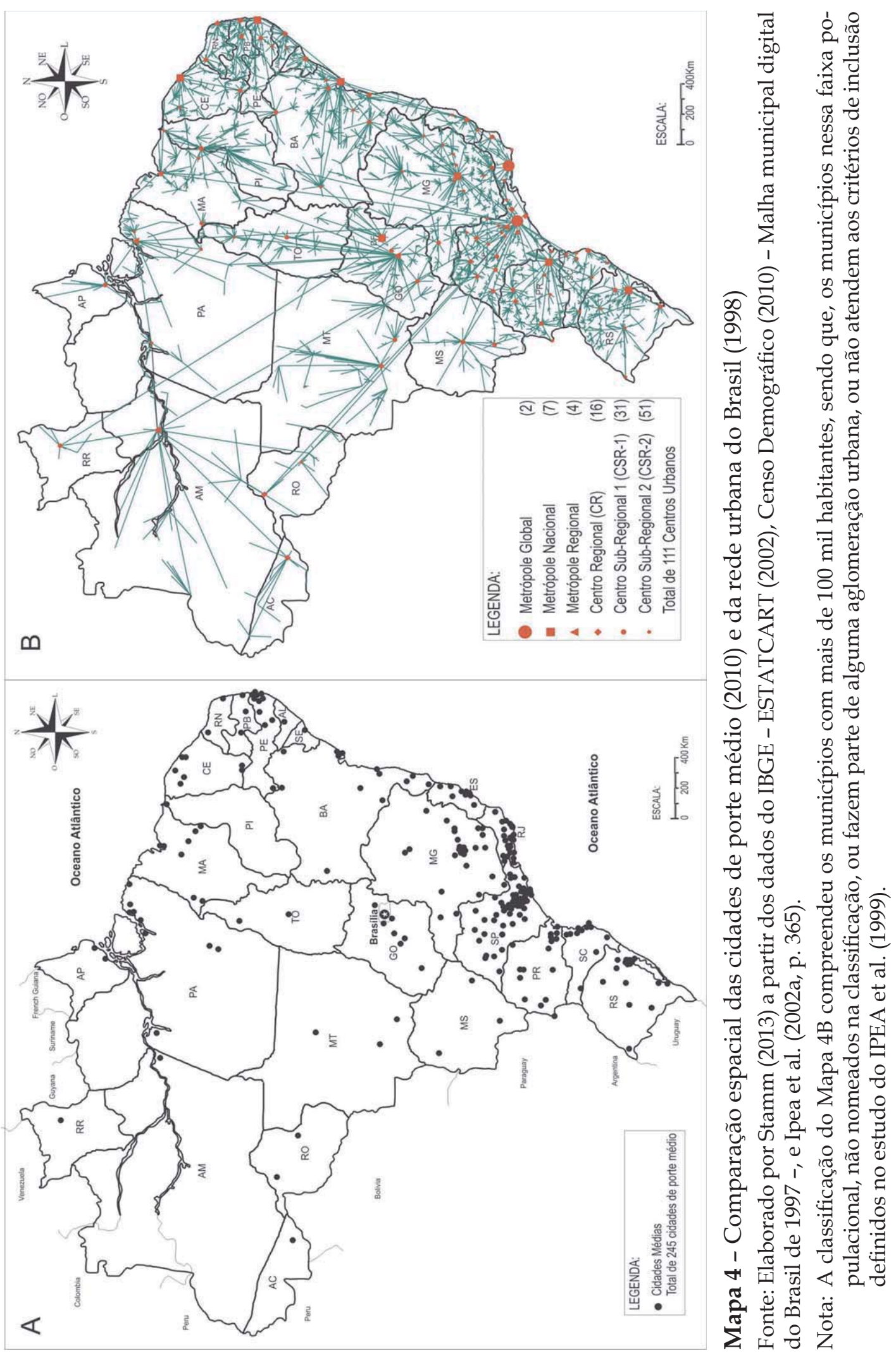
No Mapa 4, é possível observar que as cidades de porte médio, que aparecem dispostas no Mapa 4A, na sua maioria apresentam localizações coincidentes às cidades do Mapa 4B que são classificadas de centros urbanos, ou seja, os Centros Regionais (CR), Centros Sub-Regionais 1 (CSR-1) e Centros SubRegionais 2 (CSR-2), os quais são pertinentes ao estrato populacional de cidades de porte médio (entre 100 mil e 500 mil habitantes).

No Mapa 4A, foi verificado um total de 245 cidades de porte médio em 2010, enquanto no Mapa 4B foi evidenciado um total de 111 centros urbanos no país, segundo a Contagem Populacional de 1996. Do total desses 111 centros urbanos distribuídos em Metrópole Global (2), Metrópole Nacional (7), Metrópole Regional (4), Centro Regional (16), Centro Sub-Regional 1 (31) e Centro Sub-Regional 2 (51), 98 correspondiam às cidades de porte médio, considerando apenas os CR, CSR 1 e CSR 2. Cabe aqui mencionar que o Mapa 4A foi composto pelo total de habitantes urbanos de cada cidade de acordo com os dados censitários de 2010, enquanto o Mapa 4B foi constituído, segundo IPEA et al (1999), pela hierarquia funcional das cidades e com dados da contagem populacional de 1996.

Essa comparação é importante para enfocar as cidades de porte médio na atual configuração da rede urbana nacional e na dinâmica do desenvolvimento das suas hinterlândias. A semelhança entre os mapas fica evidente quando são comparadas apenas as cidades interioranas de porte médio, pois essas cidades não sofrem influência dos núcleos metropolitanos que polarizam grande parte dos municípios do seu entorno.

\section{Conclusão}

O objetivo deste artigo foi analisar a dispersão da população urbana e a difusão das cidades de porte médio no Brasil nas últimas 4 décadas. Observou-se uma grande evolução das cidades de porte médio não metropolitanas, que apresentaram índices elevados na participação da população total do Brasil. Já as cidades de porte médio metropolitanas cresceram, mas não tão expressivamente. As cidades de porte médio apresentam condições de se adaptar às novas exigências indispensáveis aos novos modos de produção. A recente emergência dessas cidades no cenário nacional cria condições de implementar projetos de planejamento urbanos para que minimizem ou não ocorram os problemas causados pela urbanização, os quais, na história recente, causaram e ainda causam problemas de difícil solução nas grandes aglomerações populacionais, tais como nas metrópoles.

No entanto, através do aumento do número de cidades de porte médio no Brasil, ocorreu um processo de desconcentração populacional das grandes metrópoles nacionais (São Paulo, Rio de Janeiro, Porto Alegre, Recife, Salvador, Belo Horizonte e Fortaleza), processo esse que se intensificou a partir dos anos 1980. Assim, as cidades de porte médio serviram, em grande parte do seu período de crescimento, como "diques" de contenção dos fluxos migratórios dos grandes centros, bem como estão induzidos principalmente à difusão de atividades mais modernas por todo território nacional e, consequentemente, a uma maior distribuição da população no sistema urbano brasileiro.

Por fim, cabe salientar que o grande responsável pela dispersão espacial da população foi a tendência à desconcentração industrial, ocorrida entre 1970 e 1990; a mobilidade da fronteira agrícola, estimulada pela modernização da agricultura, e a transferência de excedentes populacionais das zonas rurais; e os investimentos em infraestrutura, que integraram o interior do Brasil à dinâmica da economia nacional. Nesse sentido, a difusão espacial das cidades de porte médio foi uma consequência do perfil do desenvolvimento econômico brasileiro e sua urbanização. $\mathrm{O}$ resultado final foi o adensamento das cidades de porte médio litorâneas e a percolação das cidades de porte médio localizadas no interior do Brasil, em particular aquelas nas áreas limítrofes à fronteira agrícola.

Assim, a difusão espacial da urbanização brasileira no final do século XX e na primeira década do século XXI é marcada por um processo expansivo, ligado à mobilidade das terras a serem ocupadas pela agricultura itinerante; e por um processo intensivo, marcado pela ocupação definitiva das áreas produtivas. Traçando-se um comparativo com o desenvolvimento da agropecuária no Brasil, a modernização da agropecuária foi útil na liberação de mão de obra para ocupar 
os fronts pioneiros. Essa ocupação criou novos mercados em regiões consideradas "vazias" e de baixa densidade demográfica nos anos 1970. Isso demonstra o quanto a dinâmica populacional brasileira é dependente da dinâmica dos espaços rurais, a forma como ocupa a força de trabalho, e do perfil da demanda bens e serviços das áreas urbanas. Enquanto as metrópoles nacionais e regionais apresentam um continuum urbano-industrial, parte das cidades de porte médio localizadas nas áreas de ocupação recente será marcada por um continuum urbano-rural. Ao longo do século XXI, o perfil produtivo dessas cidades mudará, marcando a industrialização e a formação de mercados expressivos no interior do país. Para que isso se confirme, a economia brasileira deverá garantir a estabilidade dos preços, a conquista de novos mercados para o agronegócio brasileiro, além de atrair para alguns polos do interior do país a instalação de novas plantas industriais que, consequentemente, proporcionarão a abertura de novos postos de emprego.

Assim, de acordo com Perroux (1977), a atração de novos investimentos para o interior do país fará com que o crescimento econômico do polo se propague e se expanda, beneficiando toda a sua hinterlândia, intensificando a interação entre as cidades através da rede urbana e o desenvolvimento socioeconômico.

\section{Referências}

AMORIM FILHO, O. Cidades médias do Brasil. Revista Geografia e Ensino, Belo Horizonte, v. 3, n. 2, 1984.

AMORIM FILHO, O.; SERRA, R. V. Evolução e perspectivas do papel das cidades médias no planejamento urbano e regional. In: ANDRADE, T. A.; SERRA, R. V. Cidades médias brasileiras. Rio de Janeiro: IPEA, 2001. p. 1-34.

ANDRADE, T. A.; LODDER, C. Sistema urbano e cidades médias no Brasil. Rio de Janeiro: IPEA/INPES, 1979. (Coleção Relatórios de Pesquisa, 43).

ANDRADE, T. A.; SERRA, R. V. Distribuição espacial do emprego e do produto industrial na década de 90: possibilidades atuais para a sua investigação. In: ANDRADE, T. A.; SERRA, R. V. (Orgs.). Cidades médias brasileiras. Rio de Janeiro: IPEA, 2001a. p. 337-393.

O desempenho das cidades médias no crescimento populacional brasileiro no período 1970/2000. In: ANDRADE, T. A.; SERRA, R. V. (Orgs.). Cidades médias brasileiras. Rio de Janeiro: IPEA, 2001b. p. 129-170.

BERNARDES, Adriana. Cidades médias. In: SANTOS, Milton. Construção da nação: ocupação do território. COLÓQUIO INTERNACIONAL DE GEOCRÍTICA, 5.
2003, Barcelona. Anais... Disponível em: <http://www. mre.gov.br/cdbrasil/itamaraty/web/ port/consnac/ ocupa/procurb/cmedias/index.htm>. Acesso em: 12 jul. 2004.

BRAGA, R. Cidades médias e aglomerações urbanas no Estado de São Paulo: novas estratégias de gestão territorial. In: ENCONTRO DE GEÓGRAFOS DA AMÉRICA LATINA, 10., Anais... São Paulo, 2005.

BRITO, F.; HORTA, C. J. G.; AMARAL, E. F. L. A urbanização recente no Brasil e as aglomerações metropolitanas. Trabalho publicado pela Associação Brasileira de Estudos Populacionais - ABEP - GT Migração, 2001. Disponível em: <http://www.abep.org.br/ usuario/GerenciaNavegacao.php?caderno_id=362\&nivel=1\&texto_ $\mathrm{id}=2092>$. Acesso em: $18 \mathrm{dez} .2004$.

CASTELLS, M. A questão urbana. Rio de Janeiro: Paz e Terra, 1983.

CHRISTALLER, W. Central place in southern Germany. New Jersey: Prentice-Hall, 1966. (Original publicado em alemão em 1933).

DINIZ, C. C. Desenvolvimento poligonal no Brasil: nem desconcentração, nem contínua polarização. Nova Economia, Belo Horizonte, v. 3, n. 1, p. 35-64, set. 1993.

FERRERA DE LIMA, J. La diffusion spatiale du développement économique régional:L'analyse des composantes et de la forme de la diffusion spatiale au Sud du Brésil au $X X^{e}$ siècle. 2004. Thèse (Doctorat en Développement Régional) - DSH/Université du Québec à Chicoutimi, Saguenay. Disponível em: <http:/ / www.irec.net/01fr_ rechercheaffiche.php3?518>.

FRIEDMAN, J. A General Theory of Polarized Development. In: HANSEN, N. (Ed.). Growth Centres in Regional Development. New York: The Free Press, 1972. p. 29-41.

GEDDES, P. Cidades em evolução. Campinas: Papirus, 1994. (Coleção Ofício de Arte e Formas).

IBGE. Instituto Brasileiro de Geografia e Estatística. Sinopse do Censo Demográfico de 2010. Brasil. Disponível em: <http:/ / www.censo2010.ibge.gov.br/sinopse/index.php?dados=12\&uf=00>. Acesso em: 30 nov. 2011 a.

Estimativas das populações dos municípios em 2011. Rio de Janeiro: IBGE, 2011b. Disponível em: <http:/ / www.ibge.gov.br/home/presidencia/noticias/noticia_visualiza. php?id_noticia=1961\&id_pagina $=1>$. Acesso em: 26 ago. 2012.

\section{. Estatísticas do século XX, 2003. CD-ROM.}

Sistema de informações recuperadas georeferenciadas - Estatcart: base de informações. Rio de Janeiro: IBGE, 2002. CD-ROM.

. Censo Demográfico. Rio de Janeiro: IBGE, 1970, 1980, 1991 e 2000.

IPEA/UNICAMP.IE.NESUR/IBGE (Orgs.). Caracterização e tendências da rede urbana do Brasil. Campinas: Unicamp.IE, 1999. (Coleção Pesquisas, 3).

KON, A. Novas territorialidades: transformações nas hierarquias econômicas regionais. Revista Pesquisa $e$ Debate, São Paulo, v. 10, n. 1(15), p. 42-76, 1999.

KRUGMAN, P. Increasing returns and economic geography. Journal of Political Economy, Washington (DC), n. 99, p. 483-499, 1991. 
KRUGMAN, Paul; VENABLES, Anthony; FUJITA, Masahisa. Economia espacial. São Paulo: Futura, 2004.

LACOUR, C.; GASCHET, F. Métropolisation, centre et centralité. Revue d'Économie Régionale et Urbaine (RERU), Bordeaux, n. 1, p. 49-72, 2002.

LIMA, R. S. Expansão urbana e acessibilidade: o caso das cidades médias brasileiras. Dissertação (Mestrado) Universidade de São Paulo, Escola de Engenharia de São Carlos. São Carlos, 1998.

MARICATO, E. Brasil, cidades: alternativas para a crise urbana. Petrópolis, RJ: Vozes, 2001.

PEREIRA, A. M. A propósito das cidades médias: algumas considerações sobre Montes Claros. In: SIMPÓSIO INTERNACIONAL CIDADES MÉDIAS: DINÂMICA ECONÔMICA E PRODUÇÃO DO ESPAÇO URBANO (CIMDEPE), 1., Anais... Presidente Prudente: Unesp, 2005.

PERROUX, François. O conceito de polo de crescimento. In: SCHWARTZMAN, Jacques (Org.). Economia regional: textos escolhidos. Belo Horizonte: Cedeplar/CetredeMinter, 1977. p. 145-155.
SANTOS, M. A região cresce mais que a metrópole. In: SANTOS, Milton. Por uma economia política da cidade. São Paulo: Hucitec/Editora PUC-SP, 1994. p. 53-77.

SILVEIRA, R. L. L. Cidade, corporação e periferia urbana: acumulação de capital e segregação espacial na (re) produção do espaço urbano. Santa Cruz do Sul: EDUNISC, 2003.

STAMM, Cristiano. Determinantes do movimento de trabalhadores pendulares na algomeração urbana do nordeste do Rio Grande do Sul: uma análise a partir dos transportes coletivos. 2013. Tese (Doutorado em Planejamento Urbano e Regional) - Universidade Federal do Rio Grande do Sul (UFRGS), Porto Alegre, 2013.

. O fenômeno dos movimentos pendulares dos trabalhadores intermunicipais entre cidades de porte médio: o caso de Cascavel e Toledo (PR). 2005. Dissertação (Mestrado em Desenvolvimento Regional e Agronegócio) - Universidade Estadual do Oeste do Paraná (UNIOESTE), Toledo, PR, 2005. 